\title{
OS REFORMADORES EMPRESARIAIS DA EDUCAÇÃO: DA DESMORALIZAÇÃO DO MAGISTÉRIO À DESTRUIÇÃO DO SISTEMA PÚBLICO DE EDUCAÇÃO
}

\author{
LuIZ CARLOS DE FREITAS*
}

\begin{abstract}
RESUMO: O objetivo deste trabalho é reunir evidência empírica costumeiramente sonegada pelos reformadores empresariais da educação no Brasil e apresentar algumas das características que marcam a proposta destes "novos reformadores". As categorias centrais que definem esta política educacional envolvem uma combinação de responsabilização, meritocracia e privatização. Estuda-se a produção americana privilegiadamente porque é neste país que estas ideias foram mais largamente testadas com resultados que as caracterizam como uma verdadeira década perdida para a educação americana. No Brasil estas ideias estão crescendo, em especial ao nível das secretarias estaduais e municipais de Educação. Pretende-se alertar para os riscos destas políticas já evidenciados na pesquisa e na prática educacional.
\end{abstract}

Palavras-chave: Responsabilização. Meritocracia. Privatização. Educação pública. Avaliação.

\section{CORPORATE REFORMERS OF EDUCATION:}

FROM DEMORALISATION OF THE TEACHING TO DESTRUCTION OF THE PUBLIC EDUCATION SYSTEM

ABSTRACT: This study aims to gather empirical evidence usually skimmed by corporate reformers of education in Brazil and present some of the characteristics that mark the proposal of "new reformers". The categories that define this central educational policy involve a combination of accountability, meritocracy and privatization. This study presents the American production because it is privileged in this country; these ideas were more widely tested with results that characterize them as a true lost decade for American education. In Brazil, these ideas are growing particularly at the state and municipal education. It is intended to warn of the risks of these policies as evidenced in research and educational practice.

Key words: Accountability. Meritocracy. Privatization. Public education. Evaluation.

Pós-doutor em Educação e professor titular da Faculdade de Educação, da Universidade Estadual de Campinas (Unicamp).E-mail: freitas.lc@uol.com.br 


\section{LES REFORMATEURS ENTREPRENARIAUX DE L'EDUCATION:}

\section{DE LA DEMORALISATION DU MAGISTERE A LA DESTRUCTION DU SYSTEME PUBLIC DE L'EDUCATION}

RÉSUMÉ: L'objectif de ce travail est de réunir des évidences empiriques habituellement dissimulées par les réformateurs entreprenariaux de l'éducation au Brésil et de présenter certaines des caractéristiques qui marquent la proposition de ces "nouveaux réformateurs". Les catégories centrales qui définissent cette politique éducationnelle impliquent une combinaison de responsabilisation, de méritocracie et de privatisation. On étudie prioritairement la production américaine parce que c'est dans ce pays que ces idées furent le plus largement testées avec des résultats qui la qualifie comme une véritable décennie perdue pour l'éducation américaine. Au Brésil, ces idées sont en train de croître, particulièrement au niveau des Secrétariats d'Etat et des Municipalités de $\mathrm{l}^{\prime}$ Education. On cherche à alerter contre les risques de ces politiques déjà mis en évidence dans la recherche et dans la pratique éducationnelle.

Mots-clés: Responsabilisation. Méritocracie. Privatisation. Education publique. Evaluation.

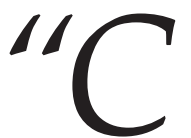

orporate reformers" - assim são chamados os reformadores empresariais da educação nos Estados Unidos, em termo criado pela pesquisadora americana Diane Ravitch ${ }^{1}$ (2011b).Ele reflete uma coalizão entre políticos, mídia, empresários, empresas educacionais, institutos e fundações privadas e pesquisadores ${ }^{2}$ alinhados com a ideia de que o modo de organizar a iniciativa privada é uma proposta mais adequada para "consertar" ${ }^{3}$ a educação americana, do que as propostas feitas pelos educadores profissionais. Naquele país, a disputa de agenda entre os educadores profissionais e os reformadores empresariais da educação vem de longa data.

Emery $(2002,2005)$ nos conta como se deu o desenvolvimento desta formulação nos Estados Unidos:

(...) os CEOs ${ }^{4}$ do Business Roundtable concordaram em que cada legislatura estadual necessitaria aprovar uma legislação que impusesse uma "educação baseada em resultados", "com expectativas elevadas para todas as crianças", "recompensas e sanções para as escolas individuais" e "maior decisão baseada na própria escola", e alinhar o desenvolvimento do quadro de pessoal com estes itens de ação. Em 1995, o Business Roundtable refinou sua agenda em "nove componentes essenciais", sendo os quatro primeiros: padrões estaduais, testes estaduais, as sanções e a transformação dos programas de formação de professores. Em 2000, os nossos CEOs tinham conseguido criar uma rede interligada de associações empresariais, fundações empresariais, associações de governadores, sem fins lucrativos, e instituições de ensino que conseguiram convencer 16 assembleias legislativas estaduais a aprovar os três primeiros componentes da sua agenda de testes de alto impacto. Esta rede incluiu o Education Trust, Annenberg Center, Harvard Graduate School, Public Agenda, Achieve, Inc., Education Commission of the States, The Broad Foundation, Institute for Educational Leadership, laboratórios regionais financiados pelo governo federal e a maioria dos conselhos editoriais dos jornais. $(2005, \text { p. } 1)^{5}$ 
Scherand Burchard (2009), a partir de uma série de reportagens sobre a era Bush e a implantação da Lei No Child Left Behind (Congresso dos Estados Unidos, 2002), afirmam:

O casamento do grande negócio com a educação beneficia não só os interesses do Business Roundtable, um consórcio de mais de 300 CEOs, mas a muitas figuras leais à família Bush. Sandy Kress, arquiteto-chefe do No Child Left Behind (NCLB); Harold McGraw III, editor de livro, Bill Bennett, secretário de Educação ex-Reagan, e Neil Bush, irmão mais novo do presidente, todos lucraram com o sucesso nacional do Roundtable na implementação do "ensino baseado em resultados". O NCLB impõe um sistema de padrões estaduais, testes e sanções para a escola, que juntos transformaram o nosso sistema de ensino público em um frenesi lucrativo. (apud Mandevilla, 2007, p. 1)

De fato, este movimento tem seu início a partir dos anos de 1980, com a publicação do relatório A Nation at Risk (National Commission on Excellence in Education, 1983), o qual apresentava um quadro de caos para a educação americana que, segundo os reformadores empresariais, comprometeria sua competitividade no cenário internacional. ${ }^{8}$ Em 1990 uma primeira formulação já estava disponível no clássico texto de Chubband Moe (1990).

Em 1995, antes mesmo da aprovação da Lei No Child Left Behind, Berliner e Biddle (1995) desmanchavam o clima de caos educacional criado pelo relatório A Nation at Risk, mas isso não impediu o avanço destas ideias naquele país. Diziam os autores:

A crise fabricada não foi um acontecimento acidental. Pelo contrário, ela apareceu dentro de um contexto histórico específico e foi conduzida por críticos identificados com objetivos políticos que podiam promover os educadores à condição de bodes expiatórios. Também foi embasada desde a sua criação por uma variedade de técnicas questionáveis - incluindo métodos enganosos de análise de dados, distorção de dados e resultados de relatórios, e supressão de evidências contrárias. Além disso, foi amarrada a esquemas equivocados para "reformar"a educação - esquemas que, se aprovados, podiam prejudicar seriamente as escolas americanas.

Infelizmente, a crise fabricada teve uma boa dose de influência - assim, muitos norte-americanos bem intencionados, brilhantes e informados passaram a acreditar em alguns desses grandes mitos, e isso tem gerado sérios danos. Programas prejudiciais para a reforma educacional foram aprovados, uma grande quantidade de dinheiro foi desperdiçada, programas escolares eficazes têm sido prejudicados e o moral dos educadores diminuiu. (p. 4)

No Brasil, movimento semelhante tem coordenado a ação dos empresários no campo da educação e é conhecido como Todos pela Educação. ${ }^{9} \mathrm{O}$ presidente do Conselho de Governança deste movimento é o megaempresário Jorge Gerdau Johannpeter, do Grupo Gerdau, que também é assessor da presidenta Dilma como coordenador da Câmara de Políticas de Gestão, Desempenho e Competitividade de seu governo. ${ }^{10}$ 
Atualmente, a Secretaria de Educação Básica do MEC está sob o comando de outro membro do Conselho de Governança do movimento, Cesar Callegari. No Conselho Nacional de Educação, atua também como conselheiro Mozart Neves Ramos - para falar apenas de algumas conexões. ${ }^{11}$ Mais recentemente, entidades empresariais e associadas na América Latina, em 11 países, passaram a compor uma frente no continente em prol destas ideias. ${ }^{12}$ Uma rede de institutos e fundações privadas se desenvolve no país, apoiando experiências e iniciativas coerentes com esta plataforma.

Para Taubman (2009), que faz uma extensa análise do discurso dos reformadores empresariais americanos, esta formulação desenvolve-se na confluência de uma série de ciências, entre elas: a psicologia behaviorista, as ciências da informação, e a neurociência. Com o apoio destes campos constrói-se uma cultura de auditoria. Nas palavras do autor: “(...) cultura de auditoria refere-se à emergência de sistemas de regulação na qual as questões de qualidade são subordinadas à lógica da administração e na qual a auditoria serve a uma forma de meta-regulação por meio da qual o foco é o controle do controle". (p. 108)

Taubman está coberto de razão. A base do entendimento dos mecanismos de controle pode ser encontrada nos trabalhos de Skinner (1972):

Os reforçadores inventados da sala de aula não se relacionam de perto com vantagens imediatas ou a longo prazo e fazem com que seja fácil, para o professor, perder de vista o significado do que está ensinando e, para os que mantêm a educação, perder contato com o que se está realmente ensinando. (p. 219, grifos meus)

Mas foi Gilbert (1978), discípulo de Skinner, quem melhor formulou uma "teoria da competência humana". A partir da diferenciação entre "comportamento" e "resultados do comportamento" ou "performance", ele postula que, para se conseguir "resultados com valor", é necessário reforçar, ou seja, premiar a performance, os resultados e não o comportamento em si. Diz ele: “(...) o comportamento tem sido visto como um fim, ao invés de ser visto como um meio para um fim" (p. 7). Na sua concepção, "(...) pessoas competentes são aquelas que podem criar resultados valiosos sem o uso excessivo de comportamentos dispendiosos" (p. 17).

Após analisar os componentes da fórmula da engenharia de desempenho, Gilbert chega à seguinte conclusão:

Para um dado resultado, a deficiência no desempenho sempre tem como sua causa imediata a deficiência no repertório comportamental, ou do ambiente que dá suporte ao repertório, ou em ambos. Mas sua causa última será encontrada na deficiência do sistema de gestão. (p. 76, grifos meus) 
Ênfase em gestão e adição de tecnologia são características da forma como os empresários fazem modificações no âmbito da produção. A lógica é transferida para o campo da educação. Essa forma de pensar a educação já havia sido detectada nos anos de 1980 e Saviani (1986) a chamou de "pedagogia tecnicista":

\begin{abstract}
A partir do pressuposto da neutralidade científica e inspirado nos princípios da racionalidade, eficiência e produtividade, (...) advoga a reordenação do processo educativo de maneira a torná-lo objetivo e operacional. (...) na pedagogia tecnicista (...) é o processo que define o que professores e alunos devem fazer, e assim também quando e como o farão. (p. 15-16)
\end{abstract}

O tecnicismo se apresenta, hoje, sob a forma de uma "teoria da responsabilização", meritocrática e gerencialista, onde se propõe a mesma racionalidade técnica de antes na forma de "standards", ou expectativas de aprendizagens medidas em testes padronizados, com ênfase nos processos de gerenciamento da força de trabalho da escola (controle pelo processo, bônus e punições), ancorada nas mesmas concepções oriundas da psicologia behaviorista, fortalecida pela econometria, ciências da informação e de sistemas, elevadas à condição de pilares da educação contemporânea. Denominamos esta formulação "neotecnicismo"(Freitas, 1992; 1995).

Este neotecnicismo se estrutura em torno a três grandes categorias: responsabilização, meritocracia e privatização. No centro, está a ideia do controle dos processos, para garantir certos resultados definidos a priori como "standards", medidos em testes padronizados.

Um sistema de responsabilização envolve três elementos: testes para os estudantes, divulgação pública do desempenho da escola e recompensas e sanções (Kane \& Staiger, 2002). As recompensas e sanções compõem o caráter meritocrático do sistema, mas não só, já que a própria divulgação pública dos resultados da escola constitui em si mesma uma exposição pública que envolve alguma recompensa ou sanção públicas. A meritocracia é uma categoria, portanto, que perpassa a responsabilização.

Ela está na base da proposta política liberal: igualdade de oportunidades e não de resultados. Para ela, dadas as oportunidades, o que faz a diferença entre as pessoas é o esforço pessoal, o mérito de cada um. Nada é dito sobre a igualdade de condições no ponto de partida. No caso da escola, diferenças sociais são transmutadas em diferenças de desempenho e o que passa a ser discutido é se a escola teve equidade ou não, se conseguiu ou não corrigir as "distorções" de origem, e esta discussão tira de foco a questão da própria desigualdade social, base da construção da desigualdade de resultados.

Dalben (2012) mostra como o desempenho final de alunos de quarta série, acompanhados entre a primeira e a quarta séries do ensino fundamental, ${ }_{13}^{13}$ está fortemente 
posicionado em relação ao desempenho inicial destes alunos no momento de sua chegada já no início da primeira série. ${ }^{14}$

\section{Gráficos 1A e 1B}

Proficiência média em cada uma das ondas de aplicação de alunos que permaneceram na mesma escola, em função do nível socioeconômico dos estudantes (NSE)

Gráfico 1A - Em matemática

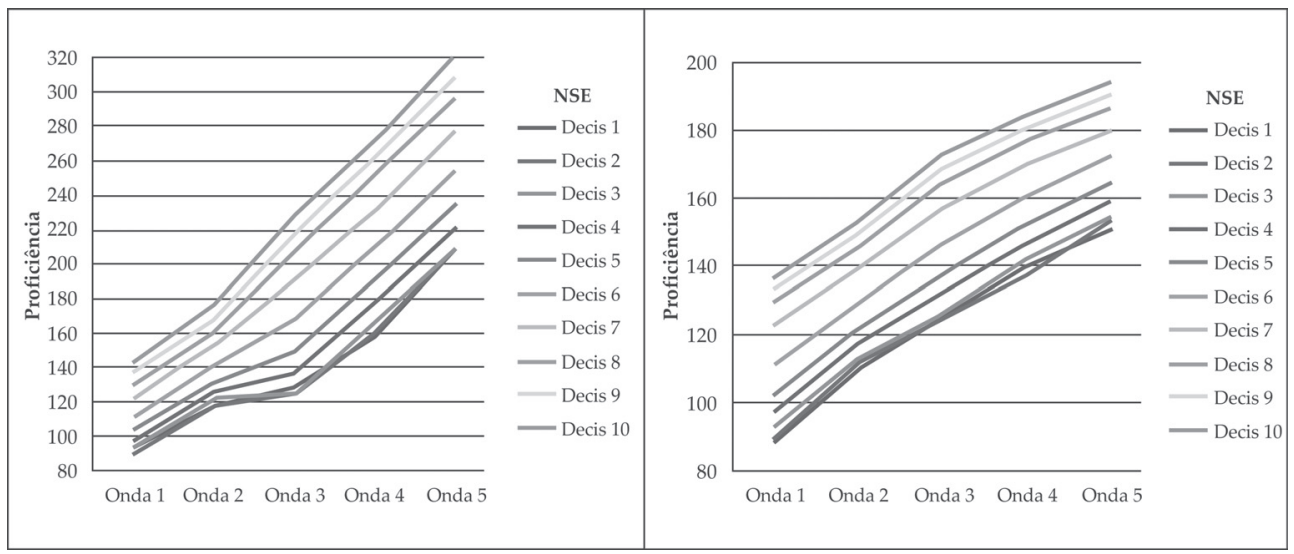

Neste gráfico, o NSE foi dividido em 10 percentis e foi calculada a proficiência média em cada um deles. O decis1 é o NSE mais alto. O termo "onda" refere-se à aplicação de testes em leitura e matemática, usando Teoria da Resposta ao Item, em escolas públicas e privadas em cinco regiões metropolitanas do país, entre 2006 e 2009. A onda 1 foi feita na chegada dos alunos nas escolas, no início do ano da primeira série. As demais ondas foram feitas ao final de cada ano letivo de cada série até a $4^{\mathrm{a}}$ série.

Como afirma o autor, "há uma alta correlação entre a proficiência inicial e a final, ou seja, quem entra com proficiência alta termina também com alta em relação aos demais alunos; e há uma alta correlação entre a proficiência inicial e o NSE do aluno. A exceção fica por conta dos três decis mais baixos, onde as proficiências médias se mesclam".

Aqui não cabe o simplismo de achar que esta distribuição dos resultados é uma questão de mera competência do professor ou da escola. Tentar resolver esta complexa relação baseado em auditoria, colocando mais pressão no sistema (cenouras e varas), faz com que o entrelaçamento das desigualdades sociais com as desigualdades acadêmicas na sala de aula e na escola seja agravado. Estudos mostram (Neal \& Schanzenbach, 2010) que o impacto dos sistemas de responsabilização pode gerar uma "corrida para o centro" em termos de desempenho dos alunos, 
prejudicando os extremos da curva, ou seja, prejudicando tanto os alunos de mais alto desempenho como os de pior desempenho. Sob pressão, os professores tendem a concentrar-se naqueles alunos que estão mais próximos da média ou dos padrões médios de desempenho, tentando maximizá-los e evitar os efeitos adversos, causando esta corrida para o centro.

Os efeitos da meritocracia, quando aplicada aos professores ou a escolas, são mais questionáveis ainda. Primeiro, porque penalizam exatamente os melhores professores por considerarem que sua motivação para trabalhar se restringe ao desejo de ganhar mais dinheiro, quando, na verdade, sem descartar este motivador, o que mais move o professor é o próprio desenvolvimento do aluno. Segundo, porque expõem todos os professores a sanções ou aprovações públicas, desmoralizando a categoria ${ }^{15}$ (Ravitch, 2012; Gates, 2012; Darling-Hammond, 2012). Terceiro, porque são aplicados métodos de cálculo para identificar os melhores e os piores professores que são inconsistentes não só ao longo do tempo, como sob várias opções de modelos de análise (Corcoran, 2010; Braun, Chudowsky, \& Koenig, 2010; Baker, 2010; Schochet \& Chiang, 2010). E, finalmente, porque os estudos mostram (Hout \& Elliott, 2011; Davier, 2011; Marshet al., 2011) que a meritocracia não tem maiores impactos na melhoria do desempenho dos alunos e acarreta graves consequências para a educação.

No Brasil, um raro pronunciamento contra o uso de bônus apareceu na Folha de S. Paulo feito por Maria Alice Setubal (2012): “O sistema de bônus cria competição danosa e afasta bons professores dos alunos ruins; a educação não é como o mercado, em que a concorrência pode ser saudável".

Sobre os impactos da meritocracia, recentemente, também a National Academy of Sciences americana afirmou que:

Os programas de incentivo baseados em testes, como concebidos e implementados nos programas que foram cuidadosamente estudados, não têm aumentado o desempenho dos estudantes o suficiente para que os Estados Unidos atinjam os níveis de realização mais altos de outros países. Quando avaliados usando testes de baixo impacto pertinentes, que são menos susceptíveis de serem inflados pelos próprios incentivos dados, os efeitos globais sobre o desempenho tendem a ser pequenos e são efetivamente zero para um certo número de programas. (Hout \& Elliott, 2011, p. 4.26)

Entretanto, a aplicação destas políticas continua sendo feita nas redes de ensino, caracterizando desperdício de recursos, como reconheceu o próprio prefeito de Nova Iorque, ao encerrar a aplicação da política de bônus naquela cidade iniciada em 2008 :

Eu acho que deveríamos ter orgulho disso - do fato de que temos a coragem de sentar-se lá e dizer que achávamos que era uma boa ideia [pagar bônus aos professores], não funcionou e estamos parando-a. Nós não vamos desperdiçar o dinheiro público. (Seifman, 2011). 
Por outro lado, experiências como esta mostram que os gestores da política descuidam frequentemente da dimensão ética de sua ação. Praticar política pública sem evidência empírica, mais do que gastar dinheiro inadequadamente, caracteriza violação da ética já que não se devem fazer experimentos sociais com ideias pouco consolidadas pela evidência empírica disponível. A avaliação mexe com a vida de alunos, professores, pais e gestores. ${ }^{16}$

Responsabilização e meritocracia são duas categorias, portanto, intimamente relacionadas. A terceira categoria é a da privatização. Pode-se dizer que, de fato, as duas primeiras visam criar ambiência para ampliar a privatização do sistema público de educação.

Esta categoria sofreu uma verdadeira mutação na última década. O conceito de público estatal e público não estatal abriu novas perspectivas para o empresariado: a gestão por concessão. Desta forma, aquela divisão fundamental entre público e privado ficou matizada. Agora, abre-se a possibilidade do público administrado privadamente. $\mathrm{O}$ advento da privatização da gestão introduziu na educação a possibilidade de que uma escola continue sendo pública e tenha sua gestão privada (público não estatal) (Pedroso, 2008). Continua gratuita para os alunos, mas o Estado transfere para a iniciativa privada um pagamento pela sua gestão. Há um "contrato de gestão" entre a iniciativa privada e o governo. ${ }^{17}$ Portanto, a bandeira da escola pública tem que ser atualizada: não basta mais a sua defesa, agora termos que defender a escola pública com gestão pública.

A outra modalidade de privatização são os vouchers ou, como é mais conhecida no Brasil, a instituição de "bolsas" que permitem aos alunos estudarem nas escolas privadas. Movimentos nesta direção já podem ser percebidos, como o Programa Universidade para Todos (Prouni - no ensino superior) e o Programa Nacional de Acesso ao Ensino Técnico e Emprego (Pronatec - no ensino médio), ambos de transferência de verbas públicas para a iniciativa privada. ${ }^{18}$

O argumento central e oportunista dos defensores desta estratégia desresponsabiliza o Estado pela educação pública. Ele diz que "assim como os ricos podem escolher as escolas nas quais querem matricular seus filhos, também os pobres devem poder fazê-lo". Mas, como é obvio, é a escola pública aberta a todos que tem que ter qualidade e, portanto, é nela que devem ser feitos investimentos para sua melhoria. Transferir recursos para a iniciativa privada só piora as escolas públicas. Diga-se, de passagem, que muitas escolas privadas aparecem melhor nas estatísticas porque elas já recebem alunos mais qualificados no ponto de partida. Incluam-se, ainda, as diversas estratégias de seleção por elas usadas na entrada e durante a estada do aluno nestas escolas, fato inaceitável para uma escola pública que, por lei, deve acolhera todos, independentemente de sua qualificação inicial ou obtida durante os estudos. 
A ideia de colocar os alunos oriundos das classes populares na "escola privada" tem a finalidade de justificar o aparecimento de uma "escola privada para pobres", ou seja, as escolas públicas geridas por concessão privada, ou subvencionadas. Os vouchers, portanto, são uma ação articulada com as escolas operadas por concessão. A rede privada clássica continuará a receber os melhores alunos com melhores níveis socioeconômicos e não é para lá que os alunos das escolas públicas migrarão (Chakrabarti \& Roy, s/d).

Este argumento também esconde o fato de que é responsabilidade do Estado garantir boa educação para todos. Portanto, a tese dos reformadores empresariais, neste ponto, termina desresponsabilizando o Estado quando convém - ou seja, quando está em jogo, por um lado, o faturamento das corporações educacionais e, por outro, o controle ideológico do sistema educacional pelas corporações empresariais para colocá-lo a serviço de interesses de mercado, estreitando as finalidades educativas. É fundamental nos contrapormos à hipocrisia que prega ser possível estarmos "todos juntos pela educação", quando os interesses hegemônicos dos empresários reduzem a educação a produzir o trabalhador que está sendo esperado na porta das empresas (Freitas, 1992). A educação de qualidade tem que ser mais que isso.

Ravitch (2011a) nos informa sobre como apareceu nos Estados Unidos esta vertente da "choice", da "escolha" da escola. Pressionados na década de 1950 a aceitar as escolas mistas (brancos e negros na mesma escola), os conservadores americanos advogaram pela "escolha", ou seja, era direito de cada um escolher onde estudar: se em uma escola de brancos ou de negros. Uma forma de contornar a determinação da Corte Suprema dos Estados Unidos que eliminava a segregação racial escolar.

Estas modalidades de privatização foram utilizadas à exaustão nos Estados Unidos e nem por isso houve melhoria no cenário educacional americano. Há dez anos que os Estados Unidos estão na média do Programme for International Student Assessment (Pisa) ${ }^{19}$ e não saem disso (OCDE, 2010). Os resultados, tanto de escolas administradas por contrato de gestão, como do programa de vouchers americano, têm sido considerados pela literatura especializada como contraditórios, para sermos benevolentes (Credo, 2009; 2010). As escolas operadas por contrato tendem a ser mais segregadas racialmente, predominando a população branca e melhor posicionada socialmente em relação à escola pública regular (Frankenberg, Siegel-Hawley \& Wang, 2011). Nos últimos quinze anos, no conjunto da nação americana, a defasagem de aprendizagem entre negros e brancos foi reduzida em inexpressivos quatro pontos, caindo de 27 para 23 pontos (Rothstein, 2008). Há bons e maus resultados, exatamente como toda escola pública regular. Os dados sugerem que as escolas administradas por contrato e as que operam por vouchers têm os mesmos problemas que as escolas públicas regulares. A manutenção destas políticas evidencia apenas a disposição ideológica de afirmar que o privado é melhor que o público. 
Mesmo os eventuais bons resultados precisam ser vistos com cautela face ao que nos revela o estudo de Watson e Ryan (2009, p. 15) na Austrália:

\begin{abstract}
Os pesquisadores, analisando o impacto dos resultados de vouchers, muitas vezes se referem a dois fatores que confundem as intenções declaradas de tais reformas políticas: as estratégias das escolas para selecionar os alunos mais desejáveis, conhecidas como "triagem", e os diferentes níveis de motivação entre os pais para escolher uma escola para seu filho (Levin, 1998). Assim, quando os governos criam um ambiente de mercado com a intenção de que as escolas se tornem mais produtivas, as escolas podem responder simplesmente selecionando estudantes de melhor desempenho, e pais de alto nível socioeconômico estão mais propensos a serem os "escolhidos". A evidência do Chile sugere que isso tenha acontecido em todo o país (Hsich e Urquiola, 2003).
\end{abstract}

Para os autores, ainda, na Austrália os vouchers provocaram uma mobilidade dos alunos da faixa superior de nível socioeconômico das escolas públicas para as escolas privadas que receberam vouchers, fazendo com que permanecessem nas escolas públicas regulares os alunos da faixa inferior de nível socioeconômico, com impacto significativo para o trabalho destas escolas. Fenômeno idêntico é apontado por Ravitch (2011a) para os Estados Unidos.

Se em termos de resultados acadêmicos estas escolas "de mercado" não apresentam desempenho consistentemente melhores que as escolas públicas regulares, se em termos de aumento de equidade os resultados são pífios, a experiência americana traz o ensinamento claro de que as condições de trabalho dos professores das escolas administradas por contrato têm piorado. Enquanto um professor de uma escola pública de Cleveland ganha 66 mil dólares/ano, o professor de uma escola por contrato ganha 33 mil dólares/ano (Bloom, 2011). Isto indica que estas estratégias de privatização têm sido usadas como forma de promover, de fato, uma "reforma fiscal" na educação e não uma "reforma educacional" ou um aumento da equidade.

A política educacional dos reformadores, portanto, não está baseada em evidência empírica consistente. Mas suponhamos que as tais evidências dessem suporte a estas categorias (responsabilização, meritocracia e privatização), considerando-as exitosas como política pública, o que, como vimos, não ocorre; mesmo assim, ainda existiriam muitas outras razões para rejeitarmos a estratégia dos reformadores empresariais da educação.

Resumimos, em seguida, algumas destas consequências como forma de alertaaos sistemas de ensino. Ao assumirmos estas políticas, estaremos igualmente assumindo uma série de riscos já devidamente documentados pela pesquisa educacional. 


\section{Estreitamento curricular}

Uma consequência destas políticas é o estreitamento do currículo escolar (Au, 2007, 2009; Ravitch, 2011a). Quando os testes incluem determinadas disciplinas e deixam outras de fora, os professores tendem a ensinar aquelas disciplinas abordadas nos testes (Madaus, Russell, \& Higgins, 2009). Avaliações geram tradições. Dirigem o olhar de professores, administradores e estudantes. Se o que é valorizado em um exame são a leitura e a matemática, a isso eles dedicarão sua atenção privilegiada, deixando os outros aspectos formativos de fora (Jones, Jones \& Hargrove, 2003). Quais as consequências para a formação da juventude? A escola cada vez mais se preocupa com a cognição, com o conhecimento, e esquece outras dimensões da matriz formativa, como a criatividade, as artes, a afetividade, o desenvolvimento corporal e a cultura.

A proposta dos reformadores empresariais é a ratificação do currículo básico, mínimo, como referência. Assume-se que o que é valorizado pelo teste é bom para todos, já que é o básico. Mas o que não está sendo dito é que a "focalização no básico" restringe o currículo de formação da juventude e deixa muita coisa relevante de fora, exatamente o que se poderia chamar de "boa educação". Além disso, assinala para o magistério que, se conseguir ensinar o básico, já está bom, em especial para os mais pobres.

Um planejamento da formação da juventude não pode ser feito olhando-se para o básico. Finlândia, um país que está no topo do Pisa, com resultados altos e consistentes, não adota este caminho (Zastrow, 2008):

\footnotetext{
Eu posso entender a hesitação de algumas pessoas nos EUA (...), porque nós muitas vezes nos perguntamos se não era melhor termos objetivos mínimos de ensino. E descobrimos que não é muito inteligente, porque é melhor ter objetivos globais de certos assuntos. Porque se você definir objetivos mínimos para as escolas você sempre vai alcançar objetivos baixos, mínimos. E é por isso que estabelecemos objetivos elevados, e eles são elevados para todos, e nós nunca estabelecemos objetivos da maneira que eles possam impedir que os professores usem sua própria capacidade de ampliar a educação. Não é o caso de limitar os métodos. Nós só falamos sobre os objetivos.
}

O argumento para justificar a limitação ao básico é que os outros aspectos mais complexos dependem de se saber o básico, primeiro. Um argumento muito conhecido no âmbito do sistema capitalista e que significa postergar para algum futuro não próximo a real formação da juventude, retirando dela elementos de análise crítica da realidade e substituindo-se por um "conhecimento básico", um corpo de habilidades básicas de vida, suficiente para atender aos interesses das corporações e limitado a algumas áreas de aprendizagem restritas (usualmente leitura, matemática e ciências). A consequência é o estreitamento curricular focado nas disciplinas 
testadas e o esquecimento das demais áreas de formação do jovem, em nome de uma promessa futura: domine o básico e, no futuro, você poderá avançar para outros patamares de formação. Todos sabemos que a juventude mais pobre depende fundamentalmente da escola para aprender, e se for limitada a sua passagem pela escola às habilidades básicas, nisso se resumirá sua formação (Saviani, 1986).

A argumentação de que o básico é bom porque tem que vir em primeiro lugar é tautológica, ou seja, nos leva a acreditar que "o básico é bom porque é básico". $\mathrm{O}$ efeito é que, a partir deste estereótipo, não pensamos mais. Com esta lógica de senso comum, são definidos os objetivos da "boa educação". Mas o básico exclui o que não é considerado básico - esta é a questão. O problema não é o que ele contém como "básico", é o que ele exclui sem dizer, pelo fato de ser "básico". Este é o "estreitamento curricular" produzido pelos "standards" centrados em leitura e matemática. Eles deixam de fora a boa educação que sempre será mais do que o básico.

Por esta mesma linha, propõe-se uma identidade entre qualidade da educação e "nota alta". Entretanto, como já alertou Ravitch (2010c), nota alta não é sinônimo de qualidade da educação:

\begin{abstract}
A lição mais importante que podemos tirar do que foi feito nos Estados Unidos é que o foco deve ser sempre em melhorar a educação e não simplesmente aumentar as pontuações nas provas de avaliação. Ficou claro para nós que elas não são necessariamente a mesma coisa. Precisamos de jovens que estudaram história, ciência, geografia, matemática, leitura, mas o que estamos formando é uma geração que aprendeu a responder testes de múltipla escolha. Para ter uma boa educação, precisamos saber o que é uma boa educação. E é muito mais que saber fazer uma prova. Precisamos nos preocupar com as necessidades dos estudantes, para que eles aproveitem a educação.
\end{abstract}

\title{
Competição entre profissionais e escolas
}

A colocação dos profissionais de educação em processos de competição entre si e entre escolas levará à diminuição da possibilidade de colaboração entre estes. A educação, entretanto, tem que ser uma atividade colaborativa altamente dependente das relações interpessoais e profissionais que se estabelecem no interior da escola (Bryk \& Schneider, 2002). Nem mesmo a ação didática de um professor se esgota apenas no tempo em que ele passa com o aluno. Afeta outros professores, pois o aluno é o mesmo. Se um deles destrói a autoestima do aluno, todos serão atingidos por este fato.

Mais uma vez, a Finlândia mostra o caminho (Zastrow, 2008):

Não, nós não fazemos isso [avaliar o desempenho da escola]. Acabamos de avaliar o desempenho dos alunos em todo o país, e não da escola. Por exemplo, quando estamos fazendo avaliação em matemática, ela é baseada em uma amostragem aleatória. E nós 
nunca divulgamos os resultados escola por escola ou município por município. Nós apenas olhamos a situação em geral do país. Não fazemos listas de classificação.

A questão que se coloca é: Por que copiamos de quem está na média do Pisa há 10 anos (EUA) e não de quem está consistentemente no topo deste programa (Finlândia)? (OCDE, 2010).

Outra não é a posição do Uruguai, para falar da América Latina. A Lei de Educação do Uruguai, em seu artigo 116, estabelece claramente que:

O Instituto Nacional de Avaliação Educacional a cada dois anos realizará um informe sobre o estado da educação no Uruguai (...). A política de divulgação desta informação resguardará a identidade dos educandos, docentes e instituições educativas, a fim de evitar qualquer forma de estigmatização e discriminação.

A pergunta novamente se impõe: Por que preferimos copiar o Chile, uma sucursal americana, e não o Uruguai, sendo que este está, em termos de América Latina, exatamente na mesma posição do Chile no Pisa? (OCDE, 2010).

\section{Pressão sobre o desempenho dos alunos e preparação para os testes}

As políticas de responsabilização pressionam os professores a obter desempenho sempre crescente de seus alunos (Congresso dos Estados Unidos, 2002). ${ }^{20}$ Para tal, associam o desempenho do aluno ao próprio pagamento dos professores. ${ }^{21}$ Premidos pela necessidade de assegurar um salário variável na forma de bônus, os professores pressionam seus alunos, aumentando a tensão entre estes. Premidos pela necessidade de apresentar sua escola como uma boa instituição à comunidade, reproduzirão práticas que tenderão a afastar de suas salas e de suas escolas alunos com dificuldades para a aprendizagem (Nichols \& Berliner, 2007).

As pressões sobre os alunos, por meio desimulados e atividades de preparação para os testes, promovem do mesmo modo o permanente desgaste dos alunos e de suas famílias. ${ }^{22}$ Recentemente, o governador da Califórnia, Jerry Brown, fez em seu discurso do ano um apelo para que haja menos testes (Strauss, 2012).

Deve-se esperar, como ocorreu nos Estados Unidos, que esta pressão estará sendo feita sobre alunos cada vez mais jovens, levando a uma escolarização antecipada da pré-escola. Os efeitos nefastos desta política para a educação infantil foram denunciados em recente relatório elaborado por pesquisadores americanos (Miller \& Almon, 2009):

O Jardim de Infância mudou radicalmente nas últimas duas décadas. As crianças já passam muito mais tempo sendo ensinadas e testadas em alfabetização e matemática do 
que fazendo a aprendizagem através da brincadeira e da exploração, exercitando seus corpos e utilizando a sua imaginação. Muitos jardins de infância usam currículos altamente prescritivos orientados aos novos padrões do Estado, ligados a testes padronizados. Em um número crescente de creches, os professores devem seguir scripts do qual não podem se afastar. Estas práticas, que não estão bem fundamentadas em pesquisas, violam os princípios de longa data estabelecidos sobre o desenvolvimento da criança e o bom ensino. É cada vez mais claro que eles estão tanto comprometendo a saúde das crianças, como suas perspectivas de longo prazo de sucesso na escola. (p. 1)

Sinais desta antecipação já começam a ser evidenciados no Brasil com o recente anúncio de mais uma prova de larga escala, agora para medir a alfabetização em crianças de 8 anos.

No Rio de Janeiro, testes americanos para serem utilizados na pré-escola encontram-se sendo validados e fizeram parte de Seminário sobre a primeira infância, ocorrido na Secretaria de Assuntos Estratégicos da Presidência da República (Brasil, 2011).

Igualmente, isso leva ao apostilamento das redes (Adrião et al., 2009) com o objetivo de se garantir um alinhamento entre o ensinado e o avaliado, produzindo ainda mais estreitamento curricular. Esse apostilamento começa na pré-escola e continua no ensino fundamental.

\section{Fraudes}

Por esta mesma linha de pressão, chega-se à fraude. Nichols e Berliner (2007) reuniram em um livro os chamados efeitos colaterais destas políticas de controle sobre a escola e seus profissionais. Entre estes, os autores recuperam um princípio formulado por Donald Campbell (1976, p. 49) que diz: “Quanto mais um indicador social quantitativo é utilizado para fins sociais de tomada de decisão, mais sujeito ele estará à pressão de corrupção e mais apto ele estará a distorcer e corromper os processos sociais que se pretende monitorar".

As evidências de fraude nos Estados Unidos são eloquentes. Uma investigação em Atlanta (Georgia, 2011) demonstrou que 58 escolas do sistema estavam comprometidas com alterações fraudulentas em notas dos alunos. A investigação levou ao afastamento da secretária da Educação local, Beverly Hall. Na cidade de Nova Iorque, John Klein deixou o cargo após denúncias de que o nível dos testes da cidade teria sido rebaixado para melhorar artificialmente as notas dos estudantes (Ravitch, 2010b). Tanto Klein como Hall são figuras importantes no movimento americano dos reformadores empresariais.

As variáveis que afetam a aprendizagem do aluno não estão todas sob controle do professor. Esta pressão e controle produzem um sentimento de impotência, 
associada à necessidade de sobreviver, que tem levado à fraude. Multiplicam-se os casos de ajuda do próprio professor durante a realização de exames, quando não a simples alteração da nota obtida pelo aluno em testes (Tucker, 2010; Georgia, 2011; Leung, 2004). Juntam-se a estes os casos de fraudes no interior das prestadoras de serviço que constroem, aplicam e corrigem os testes (Farley, 2009).

O pagamento através de bônus (Soares \& Hachem, 2010; Brooke, 2011) definidos pelo desempenho dos alunos contribui para agravar estas fraudes e desmoraliza ainda mais o magistério, além de ter-se revelado uma medida que não contribui para a melhoria do ensino (Davier, 2011; Baker, 2010; Hout \& Elliott, 2011; Springer \& Winters, 2009). Contraditoriamente, tais ideias estão sendo aceitas no Brasil pelas secretarias de Educação dos estados (Máximo, 2011).

\section{Aumento da segregação socioeconômica no território}

Estudo do Centro de Estudos e Pesquisas em Educação, Cultura e Ação Comunitária (Cenpec) (Ernica \& Batista, 2011) mostra que, com a pressão por desempenho, as escolas podem especializar-se em determinadas clientelas de estudantes, sendo deixadas no conjunto do território para a destinação de alunos de baixo desempenho. As escolas vão travando a entrada de alunos de risco e dirigindo-os a outras escolas. Como advertem os autores, há consequências geradas por estas políticas que estão além do impacto das medidas na própria escola, individualmente.

\section{Aumento da segregação socioeconômica dentro da escola}

Não é diferente dentro das escolas. Quando a seleção não ocorre na entrada, estas são levadas a fazer turmas de estudantes que se destaquem no desempenho para que "segurem" a média da escola e o acesso a benefícios. Os alunos com dificuldades vão sendo segregados em turmas separadas.

A experiência americana não revela que houve uma maior equidade, por exemplo, entre os desempenhos médios dos negros e brancos (Rothstein, 2008). Igualmente, a adoção da gestão privada da escola pública tem conduzido a mais segregação (Frankenberg, Siegel-Hawley \& Wang, 2011).

As pressões sobre o professor terminam obrigando-o a segregar os alunos que estão nas pontas dos desempenhos (mais altos e mais baixos) e concentrar-se no centro, em especial naqueles que estão próximos da média, para não irem abaixo dela e para superá-la. Esta concentração em torno da média penaliza seriamente os mais necessitados (Neal \& Schanzenbach, 2010). 


\section{Precarização da formação do professor}

O apostilamento das redes contribui para que o professor fique dependente de materiais didáticos estruturados, retirando dele a qualificação necessária para fazer a adequação metodológica, segundo requer cada aluno.

Além disso, uma visão pragmatista se instala cada vez mais nas agências formadoras do professor, restringindo sua formação aos aspectos práticos das metodologias. ONGs como a Teach for América, nos Estados Unidos, formam professores em cinco semanas (Ravitch, 2011a). O braço internacional desta organização é a Teach for All, que opera no Brasil com o nome de Ensina! (2012). No seu site pode-se ler como ela prepara os seus "ensinas":

Antes de assumir uma sala de aula, o "ensina" passa por um treinamento intensivo de dois meses, em janeiro e fevereiro. O conteúdo é desenvolvido com base nos 20 anos de sucesso da rede Teach for All e atualizado com o pensamento de educadores brasileiros. Neste treinamento inicial, que chamamos de Instituto de Verão, os "ensinas" planejam seus cursos e já entram em sala de aula, sempre acompanhados de perto por tutores experientes. Toda a prática é avaliada e discutida em grupo, num processo de feedback constante.

\section{Destruição moral do professor}

Os processos de avaliação de professores cada vez mais estão individualizando os profissionais. No Brasil, tal individualização ainda é feita tomando-se por base a escola, mas em outros países chega-se a divulgar a avaliação individual dos professores em jornais locais com grande desgaste para estes profissionais (Ravitch, 2012, 2010a). O caso mais recente é o da cidade de Nova Iorque, que divulgou a avaliação e o nome de 18 mil professores nos jornais locais, gerando ranqueamento público. Até Bill Gates objetou o procedimento (Gates, 2012).

O impacto desta política de submeter o professor a toda sorte de responsabilização e exposição pública começa a aparecer nas pesquisas sobre as percepções que professores, pais e alunos têm desta profissão (Markow \& Pieters, 2012). No ano de 2012 esta pesquisa aponta o índice mais baixo de professores satisfeitos com a profissão: caiu de 59\% para 44\%. É o nível de satisfação mais baixo em 20 anos de pesquisas de opinião nos Estados Unidos. Curiosamente, é mais baixo exatamente no momento em que o presidente dos Estados Unidos declara que a pessoa mais importante da educação é o professor. Porém, esta importância é negada na prática ao se propor uma política de pagamento de bônus em função da avaliação dos alunos.

Outra pesquisa - "Primary Sources: 2012 - America's Teachers on the teaching profession"(Maier \& Phillips, 2012) - mostra simultaneamente que apenas 26\% dos 
professores concordam em que o pagamento de bônus seja um motivador forte para seu trabalho - seja na forma de incentivo pessoal, seja na forma de incentivo coletivo à escola como um todo.

Novamente, aqui, a Finlândia tem procedimentos completamente opostos (Zastrow, 2008):

\begin{abstract}
Nós não temos qualquer avaliação de professores. Após terem sido formados na universidade têm seus documentos e obtêm um posto em uma escola. Então, ninguém avalia os professores. Nós não temos esse tipo de tradição. Nós tivemos avaliação antes, quando tivemos inspeção na Finlândia nos anos 70 e no início dos 80, mas não mais. Ninguém avalia os professores. (...) Falamos de uma cultura de confiança, e nós realmente podemos confiar neles, por causa de sua moral e ética de trabalho. É muito alta, e também podemos confiar que eles são competentes, sabem o que fazer.
\end{abstract}

\title{
Destruição do sistema público de ensino
}

Como já vimos antes, o processo de privatização avança com a concessão de escolas públicas para serem administradas pela iniciativa privada (equivalentes no Brasil às organizações da Sociedade Civil de Interesse Público - Oscip) e pela distribuição de vouchers (equivalentes ao Pronatec no Brasil). Uma proposta completa para privatizar a educação brasileira pode ser encontrada no site da Parceiros da Educação (2010). A linha central é a adoção da ideia das escolas charters americanas (privatização por concessão da gestão da escola à iniciativa privada) e a quebra da estabilidade de trabalho do professor.

A proposta ignora por completo os relatórios americanos de pesquisadores independentes, mostrando que estas estratégias de privatização nos Estados Unidos não geraram uma escola de maior qualidade do que as escolas públicas regulares. Os resultados continuam controversos, relatório após relatório (Credo, 2009, 2010; Watson \& Ryan, 2009; Ravitch, 2011a; Cobb, 2012).

Mesmo a Lei de Responsabilidade Educacional americana, a No Child Left Behind, já comentada, que inspirou a elaboração do Índice da Educação Básica (Ideb) no Brasil (Fernandes, 2007), não produziu os efeitos esperados e está sendo caracterizada como uma década perdida para a educação americana (Guisbond, Nell \& Schaeffer, 2012). Editada em 2002, a Lei determinava que até 2014 todas as crianças americanas deveriam ser "proficientes" em leitura e matemática. $\mathrm{O}$ fracasso da proposta era previsível. Entretanto, ela teve um grande efeito na promoção do fechamento das escolas públicas e sua transferência para a iniciava privada, já que estabeleceu os mecanismos legais para justificar esta transferência (Congresso dos Estados Unidos, 2002). 
Como a Lei não pode ser desrespeitada impunemente pelos estados que não vão atingir os objetivos nela estipulados, o presidente Obama foi obrigado a encontrar uma estratégia para não penalizar tais estados. Foi criada uma espécie de "perdão" para quem não atingir a Lei (Webley, 2012).

Em nosso meio, o exemplo mais esclarecedor da maneira como estas ideias atingem o sistema público de ensino, entregando seu destino à iniciativa privada, pode ser encontrado no estado de São Paulo, em documento publicado pela Ação Educativa (2012). Um conjunto de entidades e fundações privadas está financiando a empresa de consultoria McKinsey para que formule a política educacional do estado. Não é diferente nos Estados Unidos, onde meia dúzia de fundações define a agenda educacional do país (Ravitch, 2011a).

\section{Ameaça à própria noção liberal de democracia}

Para Ravitch (2010), as escolas são um patrimônio nacional público que, se for apropriado pela iniciativa privada, põe em risco a própria noção de democracia. Somente um espaço público pode lidar com a formação da juventude de forma a atender aos interesses nacionais dentro da necessária pluralidade de opiniões existentes no âmbito da sociedade..$^{23}$ Os objetivos da educação são amplos e devem, sobretudo, permitir o desenvolvimento multilateral de nossa juventude. ${ }^{24}$

Ainda há tempo para o Brasil não implementar tais políticas e evitar mais uma década perdida para a educação brasileira.

\section{Notas}

1. Para Ravitch (2011b, p. 1): “Suas ideias resumem-se a esta estratégia: a NCLB (No Child Left Behind) falhou porque não usamos suficientes cenouras e varas. Eles dizem que as escolas devem funcionar como empresas, porque o mercado livre é mais eficiente que o governo. Então, esses reformadores - eu os chamo de corporate reformers - defendem reformas baseadas no mercado".

2. Pode-se conferir isso em Ravitch (2011), em especial o capítulo 10. A primeira edição do livro foi traduzida no Brasil pela Editora Sulina (Ravitch, D. A morte e vida do grande sistema escolar americano, 2011a).

3. Termo usado pelos "corporate reformers" (Klein, Rhee \& Gorman, 2010).

4. O termo é uma abreviatura de chief executive officer, que resulta na sigla CEO, em inglês. Pode ser traduzido por diretor executivo ou diretor geral de uma empresa ou corporação.

5. Os textos de origem inglesa apresentados em português são traduções do autor deste artigo.

6. Nenhuma Criança Deixada para Trás. A lei tem 1.100 páginas. Confira em <http://www.gpo.gov/ fdsys/pkg/PLAW-107publ110/pdf/PLAW-107publ110.pdf>.

7. A Nação em Risco. 
8. Em seu discurso de posse no Ministério da Educação, o ministro da Educação Aloísio Mercadante (Mercadante, 2011) dá sinais de incorporação desta argumentação. Diz ele: "Devemos nos contentar com progressos incrementais ou devemos ousar, criar, inovar e dar um salto de qualidade que aproxime, em tempo histórico reduzido, nosso sistema educacional daqueles dos países mais desenvolvidos? Sei que se trata de um monumental desafio, mas acredito que, reunindo forças, podemos dar este salto. Mais do que isso, temos de dar este salto, caso queiramos ter competitividade internacional em todos os campos e assegurar nosso desenvolvimento em longo prazo, com inclusão social".

9. Site do Movimento disponível em: <http://www.todospelaeducacao.org.br/institucional/>.

10. Conferir em: <http://www.estadao.com.br/noticias/impresso,ceo-do-governo-dilma-escala-gerdau-paracobrar-ministros-e-definir-metas-,828592,0.htm>

11. Há também entidades mais locais com o mesmo objetivo, como é o caso da Parceiros da Educação, uma "think tank" (http://en.wikipedia.org/wiki/Think_tank) do PSDB em São Paulo, disponível em: <http://www.parceirosdaeducacao.org.br/>. Neste site encontra-se também uma proposta completa para a educação brasileira, disponível em: <http://www.parceirosdaeducacao.org.br/ evento_propostas/index.html>.

12. Conferir em: $<$ http://noticias.terra.com.br/educacao/noticias/0,,OI5352879-EI8266,00-Empresarios+ da+America+Latina+lancam+movimento+pela+educacao.html .

13. O estudo foi conduzido entre 2006 e 2009 e envolveu cerca de 300 escolas em áreas metropolitanas e mais de 20 mil alunos. Conhecido como Projeto Geres, envolveu cinco centros universitários de pesquisa e foi coordenado pelo professor Nigel Brooke. Disponível em:<http://www.geres.ufmg. $\mathrm{br} />$.

14. Conferir também: <http://www1.folha.uol.com.br/folha/educacao/ult305u677350.shtml>.

15. Recentemente, a cidade de Nova Iorque publicou o resultado nominal das avaliações de seus 18 mil professores em jornais da cidade. Los Angeles já havia feito isso antes (Felch, Song \& Smith, 2010). Em todos os casos, as margens de variação nas classificações dos professores foram grandes (cf. em: http://blogs.edweek.org/edweek/Bridging-Differences/2012/02/how_to_demoralize_teachers. $\mathrm{html}$ ). Mesmo o magnata Bill Gates, apoiador dos reformadores empresariais americanos, reagiu contra (cf. em: http://www.nytimes.com/2012/02/23/opinion/for-teachers-shame-is-no-solution. html?_r=4).

16. Recentemente, diretores das escolas do estado de Nova Iorque redigiram manifesto contra as políticas meritocráticas daquele Estado (cf. em: http://www.newyorkprincipals.org/appr-paper).

17. Nos Estados Unidos estas escolas são chamadas de "charter schools".

18. O Portal do Aprendiz já fez a proposta de um Prouni para a educação fundamental: <http://portal. aprendiz.uol.com.br/2012/03/21/um-prouni-para-a-educacao-basica-por-que-nao/>.

19. Programa Internacional de Avaliação de Estudantes (Pisa) conduzido pela Organização para a Cooperação e Desenvolvimento Econômico (OCDE). Os resultados das avaliações nacionais americanas (Naep) também não são alentadores (Ravitch , 2011a).

20. No Brasil, o equivalente desta política está em andamento no Congresso brasileiro como Lei de Responsabilidade Educacional (Brasil, 2006).

21. O estado de São Paulo e outros já praticam esta política (Costa, 2012; Máximo, 2011).

22. Pode-se acompanhar a reação de pais e alunos a esta pressão dentro dos Estados Unidos, consultando o site <www.racetonowhere.com>.

23. No Brasil, um movimento ainda inicial contra estas ideias começa a tomar forma e pode ser encontrado em: <https://sites.google.com/site/movimentocontratestes $>$.

24. No Texas, berço da Lei No Child Left Behind, um movimento consistente de administradores educacionais coloca em xeque a política de responsabilização (Texas Association of School Administrators, 2008). Uma declaração neste sentido já foi assinada por 200 Conselhos Escolares (são 1.000).

Educ. Soc., Campinas, v. 33, n. 119, p. 379-404, abr.-jun. 2012 


\section{Referências}

AÇÃO EDUCATIVA. Com incentivo de empresas, SP terá mais 100 escolas "modelo" em 2013. São Paulo: Ação Educativa, 2012. Disponível em: <http://www.acaoeducativa.org/index.php/educacao/47-observatorio-da-educacao/10004363-com-incentivo-de-empresas-sp-tera-mais-100-escolas-modelo-no-ano-que-vem>

ADRIÃO, T. et al. Uma modalidade peculiar de privatização da educação pública: a aquisição de sistemas de ensino por municípios paulistas. Educação $\mathcal{E}$ Sociedade, Campinas, v. 30, n. 108, p. 799-818, 2009.

AU, W. High-stakes testing and curricular control: a qualitative metasynthesis. Educational Researcher, Washington, DC, v. 36, p. 258-267, 2007.

AU, W. Unequal by design: high-stakes testingand the standardization of inequality. New York: Routledge, 2009.

BAKER, E.L. et al. Problems with the use os student test scores to evaluate teachers. Washington, DC: Economic Policy Institute, 2010. (Briefing paper, n. 278). Disponível em: <http://epi.3cdn.net/b9667271ee6c154195_t9m6iij8k.pdf> Acesso em: 10 nov. 2010.

BERLINER, D.C.; BIDDLE, B. J. The manufactured crisis: myths, fraud, and the attack on America's public schools. New York: Basic Books, 1995.

BLOOM, M. Sortable Table: Ohio charter school performance and costs. 2011. Disponível em: <http://stateimpact.npr.org/ohio/2011/10/19/sortable-table-ohio-charterschool-performance-and-costs/>

BRASIL. Presidência da República. Secretaria de Assuntos Estratégicos. Mesa 5: Medidas para a avaliação do desenvolvimento infantil. 26 out. 2011. Disponível em: <http:// www.sae.gov.br/primeirainfancia/\#a>

BRASIL. Projeto de Lei n. 7.420 de autoria de Raquel Teixeira. Brasilia, DF: Câmara dos Deputados, 2006.

BRAUN, H.; CHUDOWSKY, N.; KOENIG, J. Getting value out of value-added: report of a workshop. Washington, DC: National Academies, 2010. Disponível em: <http:// www.nap.edu/catalog/12820.html> Acesso em: 7 jan. 2011.

BROOKE, N. Novas políticas de incentivo salarial para professores: uma avaliação. In: FONTOURA, H.A. Políticas públicas, movimentos sociais: desafios à pós-graduação em educação em suas múltiplas dimensões. Rio de Janeiro: ANPEd, 2011. p. 163-188.

BRYK, A. S.; SCHNEIDER, B. Trust in schools: a core resource for improvement. New York: Russel Sage Foundation, 2002. 
CAMPBELL, D. Assessing the impact of planned social change. 1976. Disponível em: $<$ http://portals.wi.wur.nl/files/docs/ppme/Assessing_impact_of_planned_social_ change1.pdf> Acesso em: 15 fev. 2011.

CENTER FOR RESEARCH ON EDUCATION OUTCOMES (CREDO). Multiple choice: charter school performance in 16 states. Stanford, 2009. Disponível em: <http://credo. stanford.edu/reports/MUltiple_CHOiCE_CREDo.pdf> Acesso em: 10 nov. 2010.

CENTER FOR RESEARCH ON EDUCATION OUTCOMES (CREDO). Charter school performance in New York City. Stanford, 2010. Disponível em: <http://credo.stanford. edu/reports/NYC\%202009\%20_CREDO.pdf> Acesso em: 28 jan. 2011.

CHAKRABARTI, R.; ROY, J. Do charter schools crowd out private school enrollment?s/d. Disponível em: <http://www.newyorkfed.org/research/economists/chakrabarti/charterpublic_frbny.pdf $>$

CHUBB, J.E.; MOE, T.M. Politics, markets and America's shools. Washington, DC: Brookings Institution, 1990.

COBB, C. Review of three reports from the comprehensive longitudinal evaluation of the Milwaukee Parental Choice Program. Boulder: National Educational Policy Center, 2012. Disponível em: <http://nepc.colorado.edu/thinktank/review-Milwaukee-ChoiceYear-5>

CORCORAN, S. Can teachers be evaluated by their students' test scores? Should they be? The use of value-added measures of teacher effectiveness in policy and practice. Providence: AISR, 2010. Disponível em: <http://www.annenberginstitute.org/pdf/value AddedReport.pdf> Acesso em: 13 fev. 2011.

COSTA, M.M. Bônus muda em 2013, diz secretário de Educação de SP. IG Portal, 20 abr. 2012. Disponível em: <http://ultimosegundo.ig.com.br/educacao/2012-04-18/bonusmuda-em-2013-diz-secretario-de-educacao-de-sp.html>

DALBEN, A. O inadequado uso das avaliações seccionais de desempenho do aluno para a atribuição de sanções e bonificações à escola e ao professor. Campinas: Unicamp/Faculdade de Educação; Loed, 2012. (Não publicado).

DARLING-HAMMOND, L. The harm behind the hype. Education Week, 20 apr. 2012. Disponível em: <http://www.edweek.org/ew/articles/2012/03/05/24darlinghammond_ ep.h31.html>

DAVIER, M.V. Review of cross-country evidence on teacher performance pay. Boulder: National Education Policy Center, 2011. Disponível em: <http://nepc.colorado.edu/thinktank/ review-pisa-performance-pay> 
EMERY, K. The business roundtable and systemic reform: how corporate-engineered high-stakes testing has eliminated community participation in developing educational goals and policies. 2002. Doctoral Dissertation - University of California, Davis.

EMERY, K. Origins and purpose of No Child Left Behind. 2005. Disponível em: <http:// www.educationanddemocracy.org/Emery/Emery_NCLB.htm> Acesso em: 13 fev. 2011.

ENSINA! No mundo. 2012. Disponível em: <http://www.ensina.org.br/ensina/nomundo/s

ERNICA, M.; BATISTA, A.A. Educação em territórios de alta vulnerabilidade social na metrópole: um caso na periferia de SãoPaulo. São Paulo: Cenpec, 2011. (Informe de pesquisa, n. 3).

ESTADOS UNIDOS. CONGRESSO. No Child Left Behind Act of 2001 (Public Law 107110-Jan. 8, 2002). 2002. Disponível em: <http://www.gpo.gov/fdsys/pkg/PLAW107publ110/pdf/PLAW-107publ110.pdf>

FARLEY, T. Making the grades: my misadventures in the standardized testing industry. Sausalito: PoliPoint, 2009.

FELCH, J.; SONG, J.; SMITH, D. Grading the teachers: who's teaching L.A.'s kids? 2010. Disponível em: <http://www.latimes.com/news/local/la-me-teachers-value20100815,0,2695044.story> Acesso em: 7 fev. 2011.

FERNANDES, R. O mentor da equação: entrevista a Marta Avancini. Revista Educação, São Paulo, n. 123, jul. 2007. Disponível em: <http://revistaeducacao.uol.com.br/ textos.asp?codigo=12199>. Acesso em: 26 fev. 2011.

FRANKENBERG, E.; SIEGEL-HAWLEY, G.S.; WANG, J. Choice without equity: charter school segregation. Education Policy Analysis Archives, n. 19, p. 1-96, 2011.

FREITAS, L.C. Conseguiremos escapar ao neotecnicismo? In: SOARES, M.B.; KRAMER, S.; LUDKE, M. Escola básica (Anais da 6. CBE). Campinas: Papirus, 1992.

FREITAS, L.C. Crítica da organização do trabalho pedagógico e da didática. Campinas: Papirus, 1995.

GATES, B. Shame is no solution. New York Times, New York, 23 fev. 2012. Disponível em: <http://www.nytimes.com/2012/02/23/opinion/for-teachers-shame-is-no-solution. html?_r=4>

GEORGIA, G.D. Atlanta Public Schools. Investigative Report, v. 1-3, Jul. 2011. Disponível em: <http://www.calameo.com/books/0001070442388e8a1b081>

GILBERT, T.F. Human competence: engineering worthy performance. New York: McGraw Hill, 1978. 
GUISBOND, L.; NELL, M.; SCHAEFFER, B. NCLB's lost decade for educational progress: what can we learn. [S.1.]: National Center for Fair \& Open Testing, 2012. Disponível em: <http://fairtest.org/NCLB-lost-decade-report-home>

HOUT, M.; ELLIOTT, S.V. Incentives and test-based accountability in education. Washington, DC: National Academy of Sciences, 2011.

JONES, M.G.; JONES, B.D.; HARGROVE, T.Y. The unintended consequences of highstakes testing. Maryland: Rowman and Littlefield, 2003.

KANE, R.J.; STAIGER, D.O. The promise and pitfalls of using imprecise school accountability measures. Journal of Economic Perspectives, Nashville, v. 16, n. 4, p. 91114, 2002.

KLEIN, J.; RHEE, M.; GORMAN, P.C. How to fix our schools: a manifesto by Joel Klein, Michelle Rhee and other education leaders. The Washington Post, 10 out. 2010. Disponível em: <http://www.washingtonpost.com/wp-dyn/content/article/2010/10/07/ AR2010100705078.html>

LEUNG, R. The “Texas Miracle”. CBS News, 22 ago. 2004. Disponível em: <http:// www.cbsnews.com/stories/2004/01/06/60II/main591676.shtml> Acesso em: 22 fev. 2011.

MADAUS, G.; RUSSELL, M.; HIGGINS, J. The paradoxes of high stakes testing. Charlotte: Information Age, 2009.

MAIER, M.; PHILLIPS, V.L. Primary sources: 2012: America's teacher on the teaching profession. New York: Scholastic and Bill \& Melinda Gates Foundation, 2012.

MANDEVILLA. Bush profiteers collect billions from No Child Left Behind. 2007. Disponível em: <http://www.dailykos.com/story/2007/03/14/311754/-Bush-Profiteers-collectbillions-from-NCLB,-Part-1> Acesso em: 14 fev. 2011.

MARKOW, D.; PIETERS, A. The Metlife survey of the American teacher: teachers, parents and the economy. New York: Metlife, 2012.

MARSH, J. et al. A big apple for educators: New York City's Experiment with Schoolwide Performance Bonuses, 2011. Disponível em: <http://www.rand.org/pubs/monographs/ MG1114.html>

MÁXIMO, L. Ganho por meta é foco de estados na educação. Valor Econômico, São Paulo, 21 jan. 2011. Disponível em: <http://www.valor.com.br/arquivo/868663/ganhopor-meta-e-foco-de-estados-na-educacao $>$

MERCADANTE, A. Discurso de posse no Ministério da Educação. Portal do MEC, 2011. Disponível em: <http://portal.mec.gov.br/index.php?option=com_content\&view=art icle\&id=12224\&Itemid=380> 
MILLER, E.; ALMON, J. Crisis in the Kindergarten: why children need do play in school. College Park: Alliance for Childhood, 2009. Disponível em: <http://www. allianceforchildhood.org/sites/allianceforchildhood.org/files/file/kindergarten_ report.pdf> Acesso em: 27 fev. 2011.

NATIONAL COMMISSION ON EXCELLENCE IN EDUCATION. A Nation At Risk: the imperative for educational reform. Washington, DC: U. S. Departament of Education, 1983.

NEAL, D.; SCHANZENBACH, D.W. Left behind by design: proficiency counts and test-based accountability. Review of Economics and Statistics, Cambridge, Mass., v. 92, n. 2, p. 263-283, 2010.

NICHOLS, S.L.; BERLINER, D.C. Collateral damage: how high-stakes testing corrupts America's schools. Cambridge, Mass: Harvard Educational, 2007.

ORGANIZATION FOR ECONOMIC CO-OPERATION AND DEVELOPMENT (OCDE). Presentation of the Pisa 2010 Results. Washington, DC: OCDE, 2010. Disponível em: <http://www.oecd.org/document/7/0,3746,en_21571361_44315115_ 46635719_1_1_1_1,00.html> Acesso em: 26 jan. 2011.

PARCEIROS DA EDUCAÇÃO. A transformação da qualidade da educação básica no Brasil. 2010. Disponível em: <http://www.parceirosdaeducacao.org.br/evento_propostas/ pdf/transformacao.pdf> Acesso em: 14 dez. 2010.

PEDROSO, J.M. A consolidação do público não estatal nas políticas educacionais: um estudo a partir da transferência de fundos privados para as ONGs. Revista do HISTDBR on line, p. 175-199, 2008.

RAVITCH, D. The death and life of the great American school system. New York: Basic Books, 2010.

RAVITCH, D. Why teachers should never be rated by test scores. 2010a. Disponível em: $<$ http://voices.washingtonpost.com/answer-sheet/diane-ravitch/ravitch-whyteachers-should-ne.html> Acesso em: 8 dez. 2010.

RAVITCH, D. New York education officials are lying to the state's schoolkids. 2010b. Disponível em: <http://www.nydailynews.com/opinions/2010/03/31/2010-03-31_new_ york_state_education_officials_are_lying_to_schoolkids.html\#ixzz0npXGNIgU> Acesso em: 20 jul. 2010.

RAVITCH, D. Nota mais alta não é educação melhor. O Estado de S. Paulo, São Paulo, 2 ago. 2010c. Disponível em: <http://www.estadao.com.br/noticias/impresso,notamais-alta-nao-e-educacao-melhor,589143,0.htm> 
RAVITCH, D. The death and life of the great American school system. 2. ed. rev. ampl. New York: Basic Books, 2011.

RAVITCH, D. A morte e vida do grande sistema escolar americano. Porto Alegre: Sulina, 2011a.

RAVITCH, D. National opportunity to learn summit. 2011b. Disponível em: <http:// www.ucc.org/justice/public-education/pdfs/NatlOTL.pdf>

RAVITCH, D. How to demoralize teachers. Education Week, 23 feb. 2012. Disponível em: <http://blogs.edweek.org/edweek/Bridging-Differences/2012/02/how_to_ demoralize_teachers.html>

ROTHSTEIN, R. A Nation at Risk" Twenty-Five Years Later. 7 abr. 2008. Disponível em: $<$ http://www.cato-unbound.org/2008/04/07/richard-rothstein/a-nation-at-risk-twentyfive-years-later/> Acesso em: 25 jan. 2011.

SAVIANI, D. Escola e democracia. São Paulo: Cortez; Campinas: Autores Associados, 1986.

SCHER, A.; BURCHARD, S. Bush profiteers collect billions from No Child Left Behind - part 12 - by Mandevilla. Project Censored; Media Democracy in action, 2009. Disponível em: <http://www.projectcensored.org/top-stories/articles/12-bush-profiteerscollect-billions-from-no-child-left-behind/> Acesso em: 14 fev. 2011.

SCHOCHET, P.Z.; CHIANG, H.S. Error rates in measuring teacher and school performance based on student test score gains. Washington, DC: Institute of Education Science, U.S. Department of Education, 2010. Disponível em: <http://ies.ed.gov/ncee/ pubs/20104004/pdf/20104004.pdf> Acesso em: 6 jan. 2011.

SEIFMAN, D. Teach boo\$t a bust. New York Post, New York, 19 Jul. 2011. Disponível em: $<$ http://www.nypost.com/p/news/local/teach_boo_bust_CZUERG4v5UxWCFi0Iq89PO>

SETUBAL, M.A. Os melhores professores para as piores escolas. Folha de S. Paulo, São Paulo, Caderno 1, p. 3, 26 abr. 2012.

SKINNER, B.F. Tecnologia do ensino. São Paulo: Herder; USP, 1972.

SOARES, J.S.; HACHEM, Z.I. Gratificação para professores e funcionários de escolas de educação básica: proposta de indicador. In: DALBEN, A. Convergências e tensões no campo da formação e do trabalho docente. Belo Horizonte: Autêntica, 2010. p. 128-139.

SPRINGER, M.G.; WINTERS, M.A. New York City's School-Wide Bonus Pay Program. abr. 2009. Disponível em: <http://www.performanceincentives.org/data/files/news/ PapersNews/200902_SpringerWinters_BonusPayProgram1.pdf> Acesso em: 3 dez. 2010. 
STRAUSS, V. Gov. Jerry Brown calls for less testing. The Answer Sheet, 18 Jan. 2012. Disponível em: <http://www.washingtonpost.com/blogs/answer-sheet/post/gov-jerrybrown-calls-for-less-testing/2012/01/18/gIQAjVjy8P_blog.html>

TAUBMAN, P.M. Teaching by numbers: deconstructing the discourse of standards and accountability in education. New York: Routledge, 2009.

TEXAS ASSOCIATION OF SCHOOL ADMINISTRATORS. Creating a new vision for public education in Texas. Austin, 2008. Disponível em: <http://www.powerontexas. com/wp-content/uploads/2011/07/Visioning-Document-TASA.pdf $>$

TUCKER, C. Beverly Hall needs to retire. Ago. 2010. Disponível em: <http://blogs.ajc. com/cynthia-tucker/2010/08/26/beverly-hall-needs-to-retire/> Acesso em: 29 jan. 2011.

WATSON, L.; RYAN, C. Choice, vouchers and the consequences for public high schools: lessons from Australia. Jun. 2009. Disponível em: <http://www.canberra.edu.au/ faculties/education/educationinstitute/attachments/pdf/Choice-vouchers-and-theconsequences.pdf>

WEBLEY, K. The beginning of the end for No Child Left Behind. Time, New York, 10 Feb. 2012. Disponível em: <http://swampland.time.com/2012/02/10/the-beginningof-the-end-for-no-child-left-behind/\#ixzz1mM3W9on3>

ZASTROW, C.V. In teachers we trust: an interview with finnish education expert Reijo Laukkanen. Learning First Alliance, 29 sept. 2008. Disponível em: <http://www. learningfirst.org/teachers-we-trust-interview-finnish-education-expert-reijo-laukkanen>

Recebido em 22 de abril de 2012.

Aprovado em 15 de maio de 2012. 